\title{
Seroprevalencia de hepatitis $E$ en trabajadores de fincas porcícolas del Valle de Aburrá 2011-2012
}

\author{
Seroprevalence of hepatitis $E$ in swine farms \\ workers in Aburra Valley 2011-2012
}

\author{
Carlos Alberto Betancur, María Victoria Mejía, Sebastián Portillo • \\ Medellín (Colombia)
}

\section{Resumen}

Introducción: el virus de la hepatitis E es causa frecuente de hepatitis en Latinoamérica, pero no hay publicaciones en nuestro medio de su presencia.

Objetivo: describir la seroprevalencia de este virus en una población de riesgo como es la de trabajadores de fincas porcícolas.

Metodología: se determinó la presencia de IgG contra el virus de hepatitis E por la técnica de ELISA en 98 trabajadores de fincas porcícolas de municipios vecinos a la ciudad de Medellín.

Resultados: se encontraron 11 muestras positivas para IgG contra hepatitis E (11.25\%) en un grupo de 89 hombres y nueve mujeres con promedio de edad para los positivos de 41.7 y los negativos 35 años relacionando su seropositividad con la edad ( $\mathrm{p}=0.04)$.

Conclusión: en Colombia también existe el virus de la hepatitis E y su seroprevalencia es del $11.22 \%$ en un grupo de riesgo por contacto con una fuente contaminante como son los cerdos. (Acta Med Colomb 2013; 38: 68-70).

Palabras clave: hepatitis, hepatitis E, zoonosis.

\section{Abstract}

Introduction: hepatitis $\mathrm{E}$ virus is a frequent cause of hepatitis in Latin America, but in our country there are no publications of his presence.

Objective: to describe the seroprevalence of this virus in a population at risk as is that of the swine farm workers.

Method: we determined the presence of IgG against hepatitis E virus by ELISA test in 98 swine farm workers from neighboring municipalities to the city of Medellin.

Results: there were 11 samples positive for IgG against hepatitis E $(11.25 \%)$ in a group of 89 men and 9 women with mean age of 41.7 for the positive and 35 years for the negative by relating their seropositivity with age $(\mathrm{p}=0.04)$.

Conclusion: in Colombia also exists the hepatitis E virus and its seroprevalence is $11.22 \%$ in a risk group by contact with a contaminant source like the pigs. (Acta Med Colomb 2013; 38: 68-70).

Palabras clave: hepatitis, hepatitis E, zoonoses
Dr. Carlos Alberto Betancur J.: Internista, Profesor Titular; Lic. María Victoria Mejía M.: Bacterióloga, Msc Docente; Sebastián Portillo G.: Estudiante. Universidad CES Medellín, Antioquia (Colombia).

Correspondencia. Dr. Carlos A. Betancur J. Clínica Soma, Medellín.

E-mail: cbetancurmed@gmail.com

Recibido: 5/VI/2012 Aceptado: 7/III/2013

\section{Introducción}

El virus de la hepatitis E es un ARN virus que causa una forma aguda, autolimitada de hepatitis y fue reconocido desde 1980 de sueros recolectados en Delhi de una epidemia del año 1955 (1), su transmisión es entérica y su genoma se logró conocer en 1990 (2, 3).

La presencia de IgM anti VHE indica infección aguda, aparece tempranamente en la infección y puede persistir hasta cuatro a cinco meses en $80-100 \%$ de los casos; y la
IgG está presente en la fase de convalecencia o infección pasada, persistiendo hasta 14 años (4-7).

Hay cuatro genotipos y 24 subtipos, el 1 y 2 dan solamente en humanos, el 3 y 4 tanto en humanos como en animales (8).

Infecta los cerdos y esta es una importante fuente de transmisión del virus al hombre $(9,10)$, también afecta roedores, osos, venados, ciervos, jabalíes, mangostas y ostras, y animales domésticos como perros, gatos, caballos, monos, ratas, ovejas (11-14). 
Se han reportado casos de transmisión madre-feto $(15,16)$.

En áreas endémicas la seroprevalencia está entre el 15 y $60 \%$ (17-19). En un estudio de 18695 sueros en EE.UU. $21 \%$ resultaron positivos (11), en Latinoamérica la seroprevalencia fluctúa entre 1.1 y $14.2 \%$ (20-24).

En Colombia, sólo aparecen dos reportes no publicados presentados en el Encuentro de Investigación en Enfermedades Infecciosas de 2010 y 2012 del grupo de gastrohepatología de la Universidad de Antioquia, donde, de 77 casos de hepatitis aguda, 17 tenían IgM para hepatitis E y 4 IgG, determinando por PCR en materia fecal era del genotipo 3 (25). No conocemos más reportes de esta enfermedad viral, a pesar de que nuestras características sociodemográficas y climáticas son aptas, para su presentación, por ello la razón de esta investigación.

\section{Estudio descriptivo}

\section{Material y métodos}

Durante el periodo comprendido entre julio 2011 y enero 2012 se tomaron en municipios vecinos a Medellín (Caldas, San Pedro, Guarne), por conveniencia 98 muestras de suero de igual número de trabajadores mayores de 18 años que tenían contacto por más de un año trabajando con cerdos y aceptaron participar en el estudio firmando previamente el consentimiento informado. A todos se les hizo una encuesta sociodemográfica.

Para la realización del ensayo, se utilizaron muestras de suero. Las muestras de sangre se recogieron en tubos limpios, secos y vacíos sin anticoagulante. Posteriormente, la muestra sanguínea se separó en sus componentes por centrifugación. El suero obtenido se congeló a $-20^{\circ} \mathrm{C}$ hasta el momento de procesarlo en el laboratorio de la Universidad CES.

Para la prueba serológica se utilizó un estuche comercial de la casa DIA.PRO (Diagnostic Bioprobes) de Milán (Italia), es un inmunoenzayo (ELISA) de tercera generación para la determinación de anticuerpos anti IgG para el virus de la hepatitis $\mathrm{E}$ (VHE) en suero humano. La especificidad que se observa con esta técnica es de $99.5 \%$, no se han observado resultados falsos positivos por este método y la sensibilidad es de $100 \%$ (comparado con estuche de referencia de la FDA realizado por el laboratorio DIA.PRO)

\section{Interpretación de los resultados}

Anticuerpos anti-VHE IgG:

Negativo: <1 S/Co.

Dudoso o indeterminado: 0.9 -1.1 S/Co.

Positivo: >1.1 S/Co

\section{Resultados}

De las 98 muestras resultaron positivas 11 (11.22\%), indeterminadas dos y negativas 85. La edad fluctuó entre 20 y 62 años, siendo el promedio de edad para los positivos 41.7 años y para los negativos 35 años, relacionando la positividad con mayor edad $(\mathrm{p}=0.04)$. El contacto con cerdos varió de uno a 36 años en promedio 7.87 años, siendo en los positivos de 10.36 años y negativos siete años relacionando también el mayor tiempo de contacto con tener IgG positiva para hepatitis E pero no significativo estadísticamente ( $\mathrm{p}=0.171)$. Fueron 89 hombres y nueve mujeres, sólo una mujer fue positiva (Tabla 1).

El grado de escolaridad fue ninguno en dos personas, primaria 56, secundaria 18, tecnológica dos y universitaria 17, no relacionando con la positividad de la prueba (Tabla 1).

Recordaron haber tenido hepatitis A, siete personas y B, dos trabajadores.

Sólo una persona negó lavarse las manos y tres no lavarse antes de comer, no se puede establecer entonces relación significativa entre estas variables.

\section{Discusión}

Encontramos una seroprevalencia de $11.22 \%$ en las 98 muestras analizadas, que es un porcentaje elevado comparado con las estadísticas de países como el nuestro que son los latinoamericanos, en Brasil por ejemplo, de 996 muestras de candidatos a donantes de sangre se halló una seropositividad de $2.3 \%$ (20) y de 1059 muestras de población general, resultaron positivas $1.68 \%$ (26), en grupos de riesgo en ese país en un estudio de 1115 pacientes, la seropositividad fue en pacientes en diálisis $6.2 \%$, drogadictos intravenosos $11.8 \%$ y en $2.1 \%$ de los pacientes que tenían hepatitis no $\mathrm{A}$, no $\mathrm{B}$ (21), en Chile la seroprevalencia en 168 niños de bajo nivel socioeconómico fue de $1.2 \%$ (22) y $8 \%$ en 1360 donantes de sangre (27), en México de 3459 individuos jóvenes, el 10.5\% fueron positivos para IgG contra hepatitis E (24). Creemos que la mayor seroprevalencia que encontramos nosotros se debe a que la muestra es de una población de riesgo por el contacto con una fuente de alta contaminación como son los

Tabla 1. Resultados.

\begin{tabular}{|l|c|c|c|c|}
\hline \multirow{2}{*}{ Variable } & \multirow{2}{*}{ Categoría } & \multicolumn{3}{|c|}{ Resultados } \\
\cline { 3 - 5 } & & Positivo & Negativo & Indeterminado \\
\hline \multirow{2}{*}{ Género } & Masculino & 10 & 77 & 2 \\
& Femenino & 1 & 8 & 0 \\
\hline \multirow{2}{*}{ Escolaridad } & Ninguna & 0 & 2 & 0 \\
& Primaria & 9 & 46 & 1 \\
& Secundaria & 1 & 17 & 0 \\
& Tecnología & 0 & 2 & 0 \\
& Universitario & 1 & 16 & 1 \\
\hline \multirow{2}{*}{ Lavado antes de comer } & Si & 11 & 82 & 2 \\
& No & 0 & 3 & 0 \\
\hline Lavado de los alimentos & Si & 11 & 84 & 2 \\
& No & 0 & 1 & 0 \\
\hline Tiempo contacto con & & 10 & 7 & \\
cerdos (años) & & & & \\
\hline
\end{tabular}


cerdos (28-30). La hepatitis E como enfermedad zoonótica se ha reconocido $(9-11,31,32)$, nosotros encontramos que el mayor contacto en tiempo con el cerdo sí aumentó la seroprevalencia, pero no fue significativo estadísticamente. Una investigación semejante a la nuestra se hizo en Brasil, donde el 6.8\% de los manipuladores de estos animales resultó positiva, siendo también inferior a nuestros hallazgos $(11.22 \%)(28)$

\section{Conclusiones}

En Colombia también existe el virus de la hepatitis E y su seroprevalencia es $11.22 \%$ en un grupo de riesgo por contacto con una fuente contaminante como son los cerdos, siendo comprable con otros países latinoamericanos que fluctúa entre 2.3 y $14.2 \%$ de la población general.

\section{Referencias}

1. Vishwanathan R. Infectious hepatitis in Delhi (1955-56): A critical study: Epidemiology. Indian J Med Res 1957; 45(Suppl 1): 1-29.

2. Balayan MS, Andjaparidze AG, Savinskaya SS, et al. Evidence for a virus in non-A, non-B hepatitis transmitted via the fecal-oral route. Inter virology 1983; 20: 23-31.

3. Reyes GR, Purdy MA, Kim JP, et al. Isolation of a cDNA from the virus responsible for enterically transmitted non-A, non-B hepatitis. Science 1990; 247: 1335-1339.

4. Mast EE, Alter MJ, Holland PV, et al. Evaluation of assays for antibody to hepatitis E virus by a serum panel. Hepatitis E Virus Antibody Serum Panel Evaluation Group. Hepatology 1998; 27: 857-861.

5. Favorov MO, Fields HA, Purdy MA, et al. Serologic identification of hepatitis E virus infections in epidemic and endemic settings. J Med Virol 1992; 36: 246.

6. Dawson GJ, Chau KH, Cabal CM, et al. Solid-phase enzyme-linked immunosorbent assay for hepatitis $\mathrm{E}$ virus IgG and IgM antibodies utilizing recombinant antigens and synthetic peptides. J Virol Methods 1992; 38: 175.

7. Khuroo MS, Kamili S, Dar MY, et al. Hepatitis E and long-term antibody status. Lancet 1993; 341: 1355

8. Emerson SU, Purcell RH. Running like water--the omnipresence of hepatitis E. N Engl J Med 2004; 351: 2367.

9. Ijaz S, Arnold E, Banks M, et al. Non-travel-associated hepatitis E in England and Wales: demographic, clinical, and molecular epidemiological characteristics. J Infect Dis 2005; 192: 1166.

10. Rutjes SA, Lodder WJ, Lodder-Verschoor F, et al. Sources of hepatitis E virus genotype 3 in The Netherlands. Emerg Infect Dis 2009; 15: 381

11. Kuniholm MH, Purcell RH, McQuillan GM, et al. Epidemiology of hepatitis E virus in the United States: results from the Third National Health and Nutrition Examination Survey, 1988-1994. J Infect Dis 2009; 200: 48.

12. Nakamura M, Takahashi $\mathbf{K}$, Taira $\mathbf{K}$, et al. Hepatitis $\mathrm{E}$ virus infection in wild mongooses of Okinawa, Japan: demonstration of anti-HEV antibodies and a full-genome nucleotide sequence. Hepatol Res 2006; 34: 137-140.

13. Takahashi K, Kitajima N, Abe N, Mishiro S. Complete or near-complete nucleotide sequences of hepatitis $\mathrm{E}$ virus genome recovered from a wild boar, a deer, and four patients who ate the deer. Virology 2004; 330: 501-505.

14. Li TC, Miyamura T, Takeda N. Detection of hepatitis E virus RNA from the bivalve Yamato-Shijimi (Corbicula japonica) in Japan. Am J Trop Med Hyg 2007; 76: 170-172.

15. Khuroo MS, Kamili S, Jameel S. Vertical transmission of hepatitis E virus. Lancet 1995; 345: 1025.

16. Kumar RM, Uduman S, Rana $S$, et al. Sero-prevalence and mother-to-infant transmission of hepatitis $\mathrm{E}$ virus among pregnant women in the United Arab Emirates. Eur J Obstet Gynecol Reprod Biol 2001; 100: 9.

17. Arankalle VA, Tsarev SA, Chadha MS, et al. Age-specific prevalence of antibodies to hepatitis A and E viruses in Pune, India, 1982 and 1992. J Infect Dis 1995; 171: 447-450.

18. Clayson ET, Shrestha MP, Vaughn DW, et al. Rates of hepatitis E virus infection and disease among adolescents and adults in Kathmandu, Nepal $J$ Infect Dis 1997; 176: 763-766.

19. Tran HT, Ushijima H, Quang VX, et al. Prevalence of hepatitis virus types B through $\mathrm{E}$ and genotypic distribution of $\mathrm{HBV}$ and $\mathrm{HCV}$ in Ho Chi Minh City, Vietnam. Hepatol Res 2003; 26: 275-280.

20. Bortoliero AL; Bonametti, AM; Morimoto, HK; Matsuo, T; Reiche, EMV. Seroprevalence for hepatitis E virus (HEV) infection among volunteer blood donors of the Regional Blood Bank of Londrina, State of Paraná, Brazil. Rev Inst Med Trop Sao Paulo 2006; 48: 87-92.

21. Trinta KS; Liberto MI; Paula VS; Yoshida CF; Gaspar AM. Hepatiti E virus infection in selected Brazilian populations. Mem Inst Oswaldo Cruz 2001; 96: 25-29.

22. Ibarra H; Riedemann S; Toledo C. Seguimientos de anticuerpos contra hepatitis A y E en una cohorte de niños de bajo nivel socioeconómico A oneyearfollow-up study. Rev Med Chile 2006; 134: 139-144.

23. Ibarra H; Riedemann S; Siegel F; Toledo C; Reinhardt G. Hepatitis aguda por virus A, E y no A-E en adultos chilenos a fines de los años 90. Rev Med Chile 2001; 129: 523-30.

24. Alvarez MT; Torres J, ; Damasio L, Gómez A; Tapia R; Muñoz O. Seroepidemiology of hepatitis E virus infection in Mexican subjects 1 to 29 tears of age. Arch Med Res 1999; 30: 251-4.

25. Rendon JC, Navas MC, Hoyos MC,Cortes FM, Correa G, Sepulveda ME, Yepez N, Jaramillo s, Zuleta JJ,Almanza R. Evidencia serológica y molecular de la circulación del virus de la hepatitis E en Medellín. Infectio 2010; 14: S1:34

26. Focaccia R, Conceiçäo, OJ, Sette Junior H, Sabino E, Bassit L, Nitrini DR, Lomar AV, Lorenço R, Souza FV, Kiffer CR, Santos EB, Gonzales MP, SáezAlquézar A, Riscal JR, Fisher D. Estimated prevalence of viral hepatitis in the general population of the municipality of Säo Paulo, measures by a serologic survey of a stratified, randomized and residence-based population. Braz J Infect Dis 1998; 2: 269-284.

27. Ibarra H, Riedemann S, Reinhardt G,;Frieck P, Siegel F, Toledo C, Calvo M, Frösner G. Prevalencia de anticuerpos del virus hepatitis E en donantes de bancos de sangre y otros grupos de población en la $\mathrm{X}$ región, Chile. Rev Med Chile 1997; 125: 275-8

28. Vitral CL, Pinto MA, Lewis-Ximenez LL, Khudyakov YE, Santos D, Gaspar AM. Serological evidence of hepatitis E virus infection in different animal species from the Southeast of Brazil Mem. Inst. Oswaldo Cruz 2005; 100: 117-122.

29. Ibarra H, Riedemann S, Reinhardt G, Calvo M. Presencia de anti-VHE en un estudio de cohorte de porcinos ¿reservorio animal de hepatitis E en Chile? / Presence of anti hepatitis E virus antibodies in swine. Rev méd Chile 2007; 135: 997-1001.

30. Li XJ, Zhao CY, Fan JP, Song AJ, Wang YC, Zhang JG. Epidemiological survey on the infection of hepatitis E virus among pigs in Henan province. Zhongua Shi Yan He Lin Chuang Bing Du XueZaZhi 2008; 22: 24-6.

31. Meng XJ. From barnyard to food table: The omnipresence of hepatitis E virus and risk for zoonotic infection and food safety. Virus Res 2011; 161: 23-30.

32. Hoofnagle JH, Nelson KE, Purcell RH. Hepatitis E. N Engl J Med 2012; 367: $1237-1244$ 